\title{
FORMAS DE RECONHECIMENTO E FORÇA INTERSUBJETIVA DE GRUPO
}

\author{
Claudio Almir Dalbosco*
}

RESUMO: O ensaio busca justificar a intersubjetividade do grupo como formação humana solidária e cooperativa. Aborda o reconhecimento como força motriz de formação do grupo, deixando claro que é por meio do reconhecimento alcançado no grupo social que o ser humano confirma valores centrais à formação de sua individualidade, como autoconfiança, autorrespeito e autoestima. Na sequência, volta-se para os traços da idealização metódica de grupo delineada por Axel Honneth com base na noçáo de objeto transicional de Donald Winnicott. Por fim, faz um ingresso pontual em um pequeno texto de Piaget, escrito ainda na metade dos anos trinta do século passado. Por ver no grupo a força motriz do desenvolvimento da condição natural de cooperação e ajuda recíproca da criança, Piaget antecipa uma ideia importante da teoria honnethiana do reconhecimento.

Palavras-chave: Formação humana; Formas de reconhecimento; Objeto transicional; Intersubjetividade de grupo.

\section{WAYS OF RECOGNITION AND GROUP INTERSUBJECTIVE POWER}

ABSTRACT: This essay seeks to justify the group inter-subjectivity as humane solidary and cooperative shaping. It approaches recognition as a driving force of group formation, making clear that it is by means of recognition reached in the social group that the human being confirms central values for the shaping of his/her individuality, such as self-confidence, self-respect and self-esteem. Next, it turns to the traits of group methodical idealization outlined by Axel Honneth based on the notion of Donald Winnicott's transitional object. In the end, it ingresses punctually into a small text of Piaget, which was written in the thirties of last century. For seeing in the group the driving force of the development of the natural condition of cooperation and reciprocal help of the child, Piaget anticipates an important idea of Honnet's theory of recognition.

Keywords: Human shaping; Ways of recognition; Transitional object; Group intersubjectivity.

\footnotetext{
* Universidade de Passo Fundo, Passo Fundo, RS., Brasil. E-mail de contato: vcdalbosco@hotmail. com.
} 


\section{FORMES DES RECONNAISSANCES ET FORCE INTERSUBJECTIVE DE GROUPE}

RÉSUMÉ: L'essai vise justifier l'intersubjectivité du groupe en tant que formation humaine solidaire et coopérative. Il aborde la reconnaissance comme la force motrice de la formation du groupe, en précisant que la reconnaissance obtenue dans le groupe social fait que l'être-humain assure les valeurs fondamentales à la formation de son individualité, comme la confiance en soi, le respect de soi et l'estime de soi. Ensuite, on reprend les traces d'idéalisation méthodique de groupe décrite par Axel Honneth ancrée à la notion d'objet transitionnel, celle de Donald Winnicott. Enfin, on fait un passage rapide par un petit texte de Piaget, écrit à la moitié des années trente du siècle dernier. Lorsqu'il observe dans le groupe la force motrice du développement de la condition naturelle de coopération et d'aide mutuelle de l'enfant, Piaget anticipe une idée importante de la théorie honnethienne de la reconnaissance.

Mots-clés: Formation humaine; Formes de reconnaissance; Objet transitionnel; Intersubjectivité de groupe.

\section{Introdução}

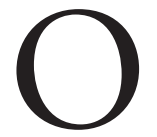

presente ensaio pretende recuperar a significação pedagógica do grupo, visando mostrar sua importância à formação de novas geraçóes numa perspectiva da solidariedade recíproca. Considero que a aposta do processo formativo-educacional humano no trabalho de grupo é um recurso indispensável para fazer frente às formas de vida cada vez mais individualistas e anônimas, produzidas pela sociedade de consumo contemporânea. Tal sociedade, baseada na globalização do mercado e impulsionada pela inovação tecnológica permanente, provoca a mercantilização não só de bens culturais, como também da política e, de modo mais amplo, do próprio espaço público, transformando cidadãos em meros consumidores.

Como mostra Habermas (1990), ao seu próprio modo, as transformaçôes estruturais da esfera pública, que começam a ocorrer a partir do século XIX, encurtam os espaços sociais da ação comunicativa, ocasionando o sombreamento da dignidade da política. Nos mesmos trilhos, mas com enfoque diferente, Sennett (1988) alerta, de modo ainda mais convincente, para o fato de que a modernidade impulsiona um processo de redução do espaço público e, com ele, o declínio do homem público, conduzindo-o à tirania da intimidade. Com este amplo processo verifica-se a transformação da política, originalmente pensada como ação pública 
visando o interesse comum (coisa pública), num simples espetáculo, pondo em risco, em última instância, a ideia de cidadania democrática. (NUSSBAUM, 2005)

A espetacularização da política e a tiranização da intimidade são fenômenos sociais contemporâneos correlatos que requerem, simultaneamente, a justificação filosófica e pedagógica do grupo como forma eficaz de enfrentá-los. Tal justificativa torna-se ainda mais urgente na medida em que se evidencia o ingresso incontido do individualismo contemporâneo no campo pedagógico, passando a dominar, por meio de tendências neo ou até mesmo pseudoconstrutivistas, o cenário pedagógico do final do século passado e início deste século. Com o enfoque reduzido aos problemas de aprendizagem no âmbito escolar da sala de aula, tais tendências distanciam educador e educando do mundo ${ }^{1}$, tangenciando o aspecto de socialização cultural mais ampla que a educação deve desempenhar. Além disso, desabilitam os envolvidos no processo educacional a ver as coisas do ponto de vista recíproco, desestimulando, em última instância, a postura de se colocar no lugar do outro. Isso conduz a suspeita de que tendências neoconstrutivistas ganham força no cenário da política educacional contemporânea porque, ao corroborarem com a ideologia pedagógica da sociedade patologicamente desorientada e narcisista, inscrevem-se tranquilamente na gramática individualista de nosso tempo.

Para mostrar a importância pedagógica do grupo como fonte de socialização moral e política do indivíduo apoio-me, nas duas primeiras partes deste ensaio, na livre reconstrução de algumas ideias de Axel Honneth, desenvolvidas num de seus últimos livros, intitulado $O$ eu em nós: estudos sobre teoria do reconhecimento (Das Ich im Wir: Studien zur Anerkennungstheorie), publicado em 2010. ${ }^{2}$ Trata-se, antes de tudo, de uma coletânea de ensaios que reinterpreta o problema do reconhecimento à luz da filosofia hegeliana do direito e, a partir disso, confronta-o com conceitos centrais da filosofia social vinculada à tradição da teoria crítica, como trabalho, ideologia, autorrealização, patologização do social e intersubjetividade de grupos.

Divido o ensaio em três partes. Na primeira, trato do reconhecimento como força motriz de formação do grupo, deixando claro que é por meio do reconhecimento alcançado no grupo social que o ser humano vê confirmados valores centrais à formação de sua individualidade, como autoconfiança, autorrespeito e autoestima. $\mathrm{Na}$ segunda parte, considerando brevemente aspectos negativos que podem resultar da má formação de grupos, sobretudo, quando conduzidos por líderes afetados patologicamente, volto-me para os traços da idealização metódica de grupo delineada por Honneth no referido livro. Contudo, para exemplificar o quanto tal idealização pode tornar-se produtiva ao campo pedagógico, incursiono, brevemente, na terceira e última parte do ensaio, num pequeno texto de Piaget, escrito ainda na metade dos anos 30 do século passado. Por ver no grupo a força motriz do desenvolvimento da condição natural de cooperação e ajuda recíproca 
da criança, Piaget antecipa uma ideia importante da teoria honnethiana do reconhecimento, mas enfocando-a do ponto de vista, especificamente, educacional.

\section{0 reconhecimento como força motriz do grupo}

Do amplo leque de conceitos que Axel Honneth lança mão para oxigenar a tradição da teoria crítica, o reconhecimento é sabidamente o mais importante. Com tal conceito ele pretende abordar filosoficamente os problemas clássicos e contemporâneos do campo político, jurídico e social, em sentido mais amplo. Embora não se volte para o campo pedagógico, seu pensamento abre frestas conceituais para compreender o cenário pedagógico contemporâneo e, sobretudo, para pensar as teorias educacionais numa perspectiva da teoria do reconhecimento.

Sua crítica mais ampla à "propensão ao cognitivismo" (Hang zum Kognitivismus) permite repor o debate, no âmbito das teorias educacionais, sobre a importância da ligação afetivo-emocional primária - ou seja, a relação da criança com o adulto que lhe está mais próximo - para a construção da individualidade humana na perspectiva da solidariedade recíproca. Neste sentido, a "simpatia existencial e afetiva pelo outro", que é central à teoria do reconhecimento como contraponto crítico ao individualismo contemporâneo, tem sua origem numa descentração bem conduzida no processo de aprendizado espiritual da criança, possibilitando-a experienciar a relação com o mundo como algo significativo. (HONNETH, 2005, p. 51)

Com isso vê-se, desde logo, a importância do "bem governar" do adulto, tanto dos pais como dos professores, na formação das novas geraçôes. Se a criança for bem cuidada desde a primeira infância - e o cuidado refere-se aqui principalmente ao ambiente afetivo-emocional que o adulto lhe deve proporcionar - obviamente que ela terá conquistado para si melhores condiçóes inicias de sua futura socialização. Terá sido bem inserida progressivamente no mundo ao mesmo tempo em que amadurece sua estrutura psíquica interna, desenvolvendo de modo equilibrado suas capacidades. Ou seja, como argumenta Honneth, baseando-se em Winnicott, como um "ser amalgamado" (Verschmolzensein), a criança pequena que possui o suporte necessário do adulto de sua referência mais próxima, desenvolve "vivências primárias" que são indispensáveis para sua vitalidade psíquica e que a influenciarão positivamente em toda sua vida, principalmente nas futuras vivências de fusão que ocorrem com sua inserção nos grupos. (HONNETH, 2010, p. 275)

A relação entre reconhecimento e grupo é umbilical, pois um não pode ocorrer sem o outro: a dependência de experiências de reconhecimento social esclarece porque o indivíduo isolado aspira a ser sujeito como membro em dife- 
rentes figurações do agrupamento social. Somente na sua relação com o grupo é que o indivíduo pode conquistar valores centrais à sua individuação. Ao longo de seu desenvolvimento o indivíduo aspira por diferentes formas de reconhecimento, as quais são sintetizadas pela autoconfiança, autorrespeito e autoestima. Honneth faz depender a cada uma delas, analiticamente, uma forma específica de membro do grupo aspirado. Assim, o autorrelacionamento infantil corresponde à autoconfiança; a socialização entre os pares da mesma idade (Peergroup) ao autorrespeito e, por último, a interação com o outro generalizado refere-se à autoestima. Considerando a importância que esta esquematização desempenha na relação entre reconhecimento e grupo, preciso analisá-la com mais cuidado.

Antes de detalhar tal esquematização, resumindo os três níveis que constituem o processo de socialização da criança, é preciso reconstruir a premissa geral que sustenta a abordagem de Honneth. O bebê aprende, segundo ele, que posiçóes motivadoras de seu parceiro de interação reportam-se aos seus traços de experiência singular ainda desorganizada visando formar o núcleo da personalidade interna que é constituído por camadas de um autorrelacionamento positivo. Dito de outro modo, a presença do adulto de referência mais próxima desafia permanentemente o bebê a internalizar atitudes e ele o faz por meio do voltar-se positivamente para si mesmo. Ora, tal processo de socialização do ser humano em sua fase inicial pode ser diferenciado na medida em que também for possível distinguir analiticamente os diferentes níveis do autorrelacionamento que fazem crescer sua capacidade autônoma. Os níveis diferenciam-se entre si porque, com o aumento dos parceiros de interaçáo, também se complexifica, tornando-se mais exigente, a própria postura de reconhecimento.

O fato é que a internalização desta exigência proporciona à criança crescida a consciência de suas capacidades e de seus direitos e deveres individuais: quanto mais ela cresce, mais exige outras formas de reconhecimento que implicam também no aumento da relação tensional com os outros parceiros de interação. Deste modo, da relação inicial direta com o adulto mais próximo e que é responsável pela sua proteção e cuidados especiais, até o nível de sua relação com o outro generalizado há um longo caminho mediado pela complexificação e enriquecimento do reconhecimento aspirado. Em síntese, a premissa geral pode ser resumida do seguinte modo: a aspiração por reconhecimento impulsiona a criança para a socialização em grupo e ao se socializar ela refina sua própria aspiração, qualificando-a cada vez mais.

Com base nesta premissa geral Honneth parte para a esquematização dos três níveis de socialização da criança. No primeiro nível, onde se encontram imbricados autorrelacionamento e autoconfiança, a criança aprende que as necessidades e desejos vivenciados internamente são compreendidos como parte da força articuladora de um indivíduo singular. O objetivo maior deste nível é alcançar a autoconfiança do bebê por meio de seu relacionamento direto com 
o parceiro de interação. Aqui pesa, sobretudo, o tipo de relacionamento que ele mantém com o adulto de sua referência mais próxima. Enfim, é por meio desta relaçáo que ele começa a constituir os primeiros traços de sua futura individuaçáo e se algo não ocorrer bem neste nível, poderá prejudicar o desenvolvimento futuro da criança, fazendo com que encontre dificuldades em sua socialização de grupo.

No segundo nível, o destaque recai para o vínculo entre a forma de grupo caracterizada pelos pares da mesma idade (Peergroup) e a forma de reconhecimento designada de autorrespeito. $\mathrm{O}$ aspecto relevante a ser frisado é que ocorre neste nível uma ampliação da rede dos parceiros significativos de interação. Além do adulto de referência mais próxima, outras crianças da mesma faixa etária entram em cena. $\mathrm{O}$ decisivo é que a criança deve aprender a construir uma forma complementar do autorrelacionamento positivo, além da já conquistada autoconfiança, que repousa na confiança elementar de se fazer valer aos olhos dos outros como um ser de capacidades. Neste novo contexto, o jogo passa a ser o principal mecanismo da internalização, propiciando à criança o desenvolvimento de formas nucleares de autorrespeito. Ao jogar ela se experencia como um parceiro de interação que, além de ter que levar a sério seus outros parceiros, também deve ser respeitada por eles, inclusive, para evitar a própria interrupção abrupta do jogo. É justamente neste sentido que o autorrespeito torna-se condição para a socialização da criança. De outra parte, o jogo também propicia à criança a formação do juízo, permitindo-lhe sentir o quanto a capacidade de julgar é importante tanto para sua autoconfiança como para seu autorrespeito, antecipando já os primeiros sinais de seu reconhecimento pela autoestima.

Este segundo nível intermediário é complementado pelo terceiro nível, no qual a autoestima se entrelaça com o outro generalizado. Este entrelaçamento proporciona um passo adiante decisivo na formação da autonomia, embora ainda continue muito próximo do segundo nível. Deste modo, para Honneth (2010, p. 266), as experiências intersubjetivas, que a criança deve fazer para construir a consciência do valor de suas capacidades sensíveis e espirituais, ocorrem num espaço-tempo no qual se adquirem as primeiras formas de autorrespeito na interação com o outro generalizado. Se nos dois níveis anteriores já ocorria a busca pela socialização no grupo, contudo, é o terceiro nível que apresenta o solo fértil para sua formação. A consciência de que as capacidades próprias de cada um são valorizadas pelos outros é algo que precisa ser confirmado ao longo da vida.

Neste sentido, a base psíquica para este modo de autorrelacionamento positivo é dado muito cedo na socialização da criança, quando os pais, os irmãos ou os colegas da mesma idade reconhecem determinadas habilidades e talentos seus. Entretanto, é com o ingresso na escola ou na profissão que se amplia e se complexifica o âmbito de avaliação da autoestima, de tal modo que em relação à ofensa adulta cresce também o desejo de concordância e confirmação. Honneth arremata seu argumento da seguinte forma: "Na necessidade de encontrar no 
círculo de correligionários uma estima diretamente vivenciada para as capacidades próprias repousa hoje um motivo, senão o principal da formação de grupos". (HONNETH, 2010, p. 269) Isso é suficiente para mostrar o quanto o reconhecimento social das capacidades próprias é fundamental para a formação da autoestima.

Com isso resumimos a esquematização formulada por Honneth para mostrar o nexo estreito entre formas humanas de aspiração por reconhecimento e formas de socialização pelo grupo. Muitos aspectos mereceriam maior aprofundamento, sobretudo, as formas de reconhecimento que são indispensáveis à formação da individualização do ser humano e que já desempenham papel importante na infância, como as já aludidas formas da autoconfiança, do autorrespeito e da autoestima. Contudo, limito-me agora a seguir a conclusão extraída por Honneth da referida esquematização.

A internalização da postura de reconhecimento construída progressivamente e de modo diferenciado conduz, assim conclui Honneth, à construção de uma forma complexa de autorrelacionamento por meio do qual a criança aprende a se compreender autonomamente como um membro competente de seu meio social. Ou seja, para que a criança possa se conceber autonomamente como um membro digno de seu ambiente social e possa ser aceita por ele como tal, ela precisa dar alguns passos em seu desenvolvimento, dos quais são decisivos, simultaneamente, tanto sua capacidade de construir uma postura de reconhecimento como de internalizá-la. Tal postura coloca-se na base de seu necessário autorrelacionamento provocado por valores como confiança, respeito e estima, os quais, por sua vez, se originam de sua interação com outros seres humanos.

Com isso fica claro também que o processo de autonomização cruza-se com o processo de socialização, pois o sujeito só pode alcançar sua individuação por meio de sua socialização. ${ }^{3}$ Isto é, somente o sujeito formado por esta relação tensional entre individuação e socialização é que pode sentir a influência das normas sociais ampliadas e dominar as capacidades que tornaram possível o núcleo prático de sua autocompreensão singular. Contudo, como alerta Honneth, para poder levar a serio tais formas de autorrelacionamento positivo e poder até mesmo ampliá-las, o sujeito precisa tornar-se membro de grupos sociais, ou seja, precisa da companhia de outros.

Neste sentido, o grupo nada mais significa do que o espelhamento da postura originária de reconhecimento que o bebê recebeu por meio de toda aquela carga emocional e afetiva que o adulto de sua referência mais próxima lhe proporcionou. No entanto, para que possa dar prosseguimento ao seu percurso de autonomização, o indivíduo precisa da socialização do grupo. Com isso passo ao segundo tópico da exposição. 


\section{Idealização metódica do grupo}

Até aqui ficou-nos claro que a aspiração humana por reconhecimento é central para a individuação da criança e que tal individuação é constituída por formas de autorrelacionamento que se tornam cada vez mais complexas na medida em que a criança amplia seus parceiros de interação: da interação inicial com o adulto de sua referência mais próxima, passando pelo Peergroup, ela alcança o outro generalizado. Como as formas de autorrelacionamento empurram a criança cada vez mais à socialização no grupo, então se torna premente investigar o sentido do próprio grupo.

Relevante para o ponto em discussão é a idealização metódica do grupo oferecida por Honneth. Mas isso não significa dizer que ele desconhece a pluralidade de grupos e a diversidade de fenômenos sociais e individuais que os diferentes grupos abrangem, envolvendo desde o medo, a insegurança e a manipulação escravizante, ${ }^{4}$ até a esperança e a proteção. Neste sentido, considera que o século XX é marcado por duas concepções antagônicas de grupo.

A primeira, formulada por Freud, passa por Canetti e chega até Adorno, concebe o grupo de forma negativa. Segundo estes autores, a experiência do grande grupo anônimo e autoritário deixa a imagem de uma massa primitiva, que regride à barbárie. Em sua obra Psicologia das massas e análise do eu, Freud é ainda mais enfático ao considerar a vida em grupo como responsável pelas regressōes que motivam os membros a se sujeitar aos líderes onipotentes e fantasiosos. Segundo ele, não são só os defeitos psicológicos individuais, mas também a atmosfera destrutiva do grande grupo anônimo que enfraquece as capacidades de autodomínio. ${ }^{5}$ Adorno, por sua vez, profundamente impactado pelo fenômeno de massa do movimento nazifascista manteve-se durante muito tempo próximo às posiçóes de Freud. Nesta fase de seu pensamento vê o sujeito, em suas experiências de grupo, como incapaz de exercer controle sobre suas energias psíquicas. Contudo, posteriormente, irá conceber a proximidade íntima entre os homens como pressuposição compreensível à ideia de humanidade, atribuindo à pertença a grupos a condição do vínculo humano próximo.

A segunda concepção, diferentemente da primeira, baseia-se na redescoberta que a psicologia social americana faz sobre a função civilizatória dos grupos de jogos e de amizade. Tal redescoberta remonta aos estudos empreendidos pelo jovem Piaget sobre o desenvolvimento moral da criança e o significado socializador dos grupos da mesma idade (Peergroup). Neste contexto, destaca-se, como uma das contribuiçóes da psicologia social americana, os estudos de James Youniss. Este autor influenciou decisivamente o debate dos anos 70 do século passado ao apresentar uma apropriação criativa e consistente das ideias do jovem Piaget. É por meio da relação com os pares da mesma idade que, segundo Youniss, a criança não 
só descobre relacionamentos simétricos como os torna central na constituição de seu Selft. Além disso, é por meio de tais relacionamentos que ela começa a formar as noçóes mínimas de respeito recíproco e de solidariedade social. (YOUNISS, 1994, p. 156)

Estas duas noçóes de grupo contraditórias entre si, uma marcada pela interpretação freudiana e, outra, pela do jovem Piaget, servem de parâmetro para que Honneth tome a noção de objeto transicional de Winnicott com o intuito de idealizar metodicamente sua própria noção. Com tal idealização ele quer mostrar o quanto o grupo é indispensável à individuação social do ser humano, buscando evitar a um só tempo tanto o negativismo como o otimismo. Para realizar seus propósitos, conta com o recurso conceitual ao objeto transicional (transitional objects) de Winnicott. ${ }^{6}$

O significado do objeto transicional e seu papel de mediação só podem ser compreendidos na medida em que se esclarecer a unidade simbiótica que se estabelece entre bebê e mãe ou o outro adulto de sua referência mais próxima. Segundo Winnicott, o bebê aprende a organizar suas forças psíquicas somente com a ajuda da internalização de modelos primários proporcionados por cuidados estáveis da mãe. Se isso procede, então o estado de vivência pressupóe uma unidade, ou seja, a inexistência de diferença entre sujeito e realidade, que impede a independência de um em relação ao outro. Unidade simbiótica significa, portanto, o total estado de dependência entre bebê e mãe em sua fase inicial. No contexto do desenvolvimento infantil isso significa dizer que os impulsos e desejos do bebê estão profundamente entrelaçados com as reações de satisfação correspondentes do adulto de referência mais próxima de tal modo que não há vazio ou distância, em sua experiência afetiva, entre seu si mesmo (Self) e a realidade.

O problema que se coloca desde o início sobre a necessária independência da criança em relação à realidade - e aí reside a contribuição original de Winnicott que interessa à Honneth - é que não se trata somente da produção cognitiva de um esquema da realidade, mas sim de mecanismos que possam colocar a criança na condição de reconhecer afetivamente a realidade do adulto de referência mais próxima como independente de suas próprias fantasias de desejo. Ora, justamente para esclarecer este passo decisivo de aprendizagem da criança pequena é que Winnicott postula a hipótese do objeto transicional. Trata-se de uma zona experimental intermediária que é concretizada, além da presença de todos os participantes, por uma esfera ontológica que possui a função de suspender a pergunta pela realidade, visando elevar a unidade simbiótica originária para outro nível.

O objeto transicional refere-se, portanto, aos objetos intermediários de referência, cumprindo o papel de ser uma espécie de formação substituta da mãe para a realidade externa. Ora, porque os objetos de referência possuem ontologi- 
camente uma natureza híbrida, a criança pode utilizá-los, praticamente diante dos olhos dos pais, para deixar sobreviver suas fantasias de simbiose originárias sobre as experiências de separaçáo e, ao mesmo tempo, intervir criativamente na realidade. Neste sentido, trata-se de um tipo de emprego brincalhão, real e experimentador, mostrando que o objeto transicional não pode ser limitado somente ao papel de manter-se associado simbioticamente à mãe vivenciada. Com o recurso a tal objeto, a criança desenvolve também ataques violentos e tentativas de destruição.

Num modo de proceder brincando com o objeto possuído afetivamente a criança procura ultrapassar (saltar), sempre simbolicamente, o abismo vivenciado dolorosamente entre a realidade interna e externa. Constituído principalmente como esfera de mediação, o objeto transicional é o lugar de nascimento psíquico de todo o interesse das futuras objetivaçôes culturais do adulto. Trata-se, com isso, formulado quase poeticamente, do âmbito de experiência intermediária que se desenvolve diretamente do âmbito de jogo da criança pequena que se perdeu em seu próprio jogo. No dizer do próprio Winnicott: "Este domínio intermediário desenvolve-se diretamente do domínio do brincar das crianças pequenas que se perdem em sua própria brincadeira”. (WINNICOTT, 2002a, p. 24) De outra parte, o objeto transicional conduz à ideia de que o homem mantém ao longo de sua vida a tendência de retornar para traz do eu limite alcançado para poder suportar a distância crescente em relação ao estado originário da simbiose.

Estas observações gerais sobre o objeto transicional servem enormemente a Honneth. Ele começa por indicar o limite crucial de Winnicott: ele não aborda a vida intersubjetiva no grupo. ${ }^{7}$ Contudo, é possível tomar o que o psicanalista inglês tratou na esfera do eu como modelo para interpretar o que o ser humano descobre na esfera cultural mais ampla. Neste sentido, quando começa a prática comum da distância psíquica entre os membros do grupo e cresce o sentimento da concordância afetiva, isso ajuda muito a cada membro do grupo suavizar a pressão de ter que aceitar a realidade externa como uma entidade independente.

As observações fascinantes de Winnicott deixam-se ampliar no sentido de que, ao lado da arte e da religião, também a intersubjetividade do grupo forma um âmbito de experiência que enfraquece os limites entre a realidade interna e externa. Segundo Honneth, se tomarmos a sério a indicação dessa zona intermediária do jogo infantil, somos levados a supor que a experiência de fusão no grupo representa para o adulto a reflexão direta de suas próprias experiências infantis. $\mathrm{O}$ aspecto importante a ser destacado é que a vida intersubjetiva no grupo é constituída a partir de tendências de fusão, mostrando o aspecto tensional que perfaz a relação entre individuação e socialização: pelo grupo o sujeito se independiza e, ao mesmo tempo, recupera aquela simbiose originária que o avanço em seus níveis de reconhecimento foi enfraquecendo e que, contudo, continua sendo decisiva à construção intersubjetiva do laço social. 
A intersubjetividade do grupo é, portanto, a idealização metódica alcançada por Honneth mediante a ampliação do papel de mediação que o objeto transicional desempenha na relaçáo dolorosa que a criança estabelece entre sua realidade interna e a realidade externa. $\mathrm{O}$ autor frankfurtiano atribui ainda, neste contexto, vários traços à idealização metódica do grupo:

a) a vida intersubjetiva do grupo proporciona a fusão intensiva entre seus membros;

b) esta experiência de fusão coletiva permite estreitar a distância entre os membros do grupo e desenvolver sentimentos de solidariedade;

c) esta fusão reanimada (wiederbelebte Fusion) do grupo permite aos membros partilhar o sentimento comum de respeito às normas ou valores, proporcionando-lhes o reconhecimento recíproco.

Antes de finalizar este tópico, cabe recorrer de modo literal a uma passagem do texto de Honneth que resume bem sua tese nuclear sobre a importância do grupo à socialização humana. Assim afirma ele:

O eu procura o nós da vivência em comum do grupo porque ele lhe garante tanto o amadurecimento como as formas de reconhecimento social, as quais lhe proporcionam diretamente o aspecto denso de encorajamento e confirmaçáo. Nem seu autorrespeito e nem sua autoestima podem ser alcançados sem a experiência protetora tornada possível pela prática de valores partilhados no grupo. (HONNETH, 2010, p. 279)

Com esta breve reconstrução da idealização metódica do grupo, conquistada por meio da apropriação específica do objeto transicional de Winnicott, penso ter alcançado o ponto forte do nexo buscado por Honneth entre reconhecimento e grupo, na medida em que ele toma tal nexo como aspecto constitutivo da própria relação tensional entre individuação e socialização. No próximo e último tópico do ensaio vou recorrer ao pensamento do jovem Piaget para endereçar minha reflexão especificamente ao campo pedagógico. De qualquer sorte, a partir da reconstrução do pensamento de Honneth, anteriormente feita, já é possível afirmar que uma "boa" educação só é possível enquanto processo mediado pela intersubjetividade do grupo. Ora, é por meio de tal intersubjetividade que se alcança o reconhecimento recíproco, tomado como mola propulsora de uma educação solidária 


\section{Força pedagógico-intersubjetiva do grupo}

Sem desconsiderar a imagem negativa do grupo e o potencial altamente destrutivo que lhe pode estar inerente, sobretudo, quando conduzido por lideranças onipotentes e doentias, Honneth se interessa por sua idealização metódica, inspirando-se no significado atribuído por Winnicott ao objeto transicional. Como vimos, atribui à intersubjetividade do grupo aquele potencial altamente construtivo que a simbiose originária com a mãe desempenha na formação psíquico-afetiva do bebê. Infelizmente, Honneth não se interessa diretamente pelas implicações e alcances pedagógicos de seu próprio pensamento. Contudo, para mostrar que tal pensamento está mesmo assim, ainda que de modo implícito, recheado de implicações pedagógicas, gostaria agora de complementá-lo por algumas ideias de Piaget.

Curiosamente, o próprio Piaget epistemólogo, inventor da epistemologia genética, distanciou-se consideravelmente de suas intuições morais juvenis e, sobretudo, de sua valiosa pesquisa sobre a formação do juízo moral na criança. Este distanciamento levou-o a assumir cada vez mais a "propensão ao cognitivismo", enfatizando os estágios do desenvolvimento, o esforço em justificar psicologicamente uma teoria do conhecimento e, por fim, em acentuar a crença no poder do pensamento lógico-formal. Esta tendência, assumida por seu pensamento maduro, sofre a objeção nuclear de que a primazia por problemas epistemológicos levou-o a menosprezar o quanto as condiçóes sociais e culturais do conhecimento influenciam no desenvolvimento infantil. (SCHARLAU, 1996, p. 147 $)^{8}$ Contudo, sua produção intelectual dos anos vinte e trinta do século passado vão justamente numa direção contrária e, por isso, livra-se de tal objeção, na medida em que, como ainda veremos, sustenta o nexo estreito entre razão e fatores sociais e, também, o papel que o trabalho cooperativo de grupo desempenha na formação da capacidade humana de pensar.

No ensaio intitulado "Observaçóes psicológicas sobre o trabalho em grupo", publicado em 1935, Piaget alude inicialmente para duas preocupaçôes centrais que estariam na base da metodologia do trabalho em grupo que passou a ganhar espaço no cenário pedagógico do início do século XX. A primeira, de natureza sociológica, deriva da ênfase crescente atribuída ao fator coletivo por diversas ideologias políticas, convencendo educadores a adotar procedimentos metodológicos e estratégias pedagógicas baseadas no trabalho em grupo dentro da sala de aula. A segunda preocupação, certamente impulsionada pela primeira, origina-se do esforço de profissionais que, ao buscar respeitar a criança como criança e ao pensar a organização do processo pedagógico de acordo com os resultados já obtidos pela psicologia do desenvolvimento infantil, “[...] foram levados à idéia do trabalho em grupo, porque a criança, tendo chegado num certo grau de 
desenvolvimento, tende espontaneamente à vida coletiva e ao trabalho em comum [...]”. (PIAGET, 1998, p. 138)

Em síntese, um cenário político favorável à vida coletiva, aliado à convicção pedagógica de que há uma tendência natural da criança ao grupo, formam o pano de fundo motivacional que posicionou a metodologia do trabalho em grupo no centro do debate educacional das primeiras décadas do século passado. Ora, é esta tendência espontânea da criança ao grupo que interessa primeiramente a Piaget.

Esclarecedor, para o nosso contexto, é o confronto que o genebrino estabelece entre a escola tradicional e a escola nova, uma vez que nos auxilia compreender porque, se para a primeira, a metodologia do trabalho em grupo é irrelevante, já para a segunda torna-se um procedimento pedagógico determinante. Partindo de uma concepção epistemológica que iguala a estrutura mental da criança com a do adulto, o modo tradicional de educar baseia-se na transmissão do conhecimento, pressupondo a capacidade memorizadora e o treinamento como recursos pedagógicos eficientes para o aprendizado da criança. $\mathrm{O}$ aspecto característico desta teoria educacional é que a escola reduz a interação social à relação entre professor e aluno: como o professor domina o conteúdo e as técnicas de aprendizagem, então, para aprender, o aluno precisa estar submetido inquestionavelmente à sua autoridade. Disso derivam-se duas consequências claras para o processo pedagógico: a) uma relação vertical e autoritária entre professor e aluno e; b) uma desconsideração ou desconhecimento sobre a importância da socialização das crianças entre si para seu próprio desenvolvimento sensório-motor, cognitivo e moral.

Piaget procura refutar esta "[...] visão simplista das tarefas do ensino e da educação intelectual [...]” (PIAGET, 1998, p. 138), recorrendo a três argumentos, os quais, entrelaçados um ao outro, procuram mostrar a indispensabilidade do trabalho cooperativo dos alunos entre si. A reconstrução pontual destes três argumentos serve aos meus propósitos, uma vez que por meio do resumo de seu conteúdo já podemos visualizar o quanto as intuições e conclusões de Piaget exemplificam pedagogicamente, de modo extraordinário, a base filosófica oferecida por Honneth para justificar a importância da intersubjetividade do grupo à formação humana.

$\mathrm{O}$ primeiro argumento, sendo inerente à natureza do trabalho docente, revela a dificuldade que o professor possui, de modo geral, de se tornar compreensível junto aos alunos. Se não for devidamente tratada, tal dificuldade pode conduzir o trabalho docente de um extremo ao outro, da condução autoritária e inquestionável ao espontaneismo faceiro e irresponsável. $\mathrm{O}$ núcleo de tal dificuldade repousa na concepção equivocada de que o verbalismo seria o procedimento pedagógico mais adequado para ensinar a criança. Piaget formula precisamente 
sua objeção: "A criança não é um ser passivo cujo cérebro deve ser preenchido, mas um ser ativo, cuja pesquisa espontânea necessita de alimento [...]". (PIAGET, 1998, p. 139) Ora, com tal objeção ele, além de por em dúvida a exclusividade da relação pedagógica entre professor e aluno e da centralidade que a aula baseada no trabalho individual assumia na educação verbalista, pôe no centro do processo formativo o trabalho conjunto e a formação de grupos. Piaget vê no trabalho de grupo, portanto, a estratégia pedagógica mais apropriada para provocar a passagem da mera recepçáo passiva para a pesquisa e à formação do espírito inquiridor dos alunos, oportunizando a cooperação e a troca entre eles.

O segundo argumento repousa na compreensão adequada do mundo infantil. Tal argumento remete a uma das perguntas mais elementar do processo pedagógico: quem é a criança ou o educando, para o qual dirigimos nossa preocupação pedagógica? $\mathrm{Na}$ medida em que a prática educativa e o trabalho investigativo mostram que a mente da criança é dominada, em sua fase inicial, por uma estrutura que é mais sensitiva do que racional, então esta é uma descoberta importante que permite reorganizar, de modo completamente diferente, o processo pedagógico. Não é de modo lógico-formal que a criança pequena começa a exercitar o seu pensamento, mas sim de modo sensitivo, por meio do jogo e da brincadeira. Sendo assim, não se pode querer preencher o que ela ainda não dispóe de modo desenvolvido, isto é, a memória, mas sim a tarefa educacional toda consiste em como formar o pensamento. Neste contexto, o trabalho de grupo é fundamental: "Com efeito, a verdade, como todo bem moral, só é conquistada pelo esforço livre, e o esforço livre na criança tem por condução natural a colaboração e a ajuda recíproca [...]". (PIAGET, 1998, p. 140)

O terceiro e último argumento, que é o mais decisivo, repousa na ideia de "[...] que a razão implica um elemento social de cooperação [...]". (PIAGET, 1998, p. 140) Ao postular esta tese, Piaget insere-se nitidamente numa longa tradição intelectual que defende a influencia direta da base social na formulação das ideias. Aqui ele está muito mais próximo da tradição da teoria crítica do que inicialmente poderíamos imaginar. Neste sentido, ao mostrar o nexo estreito entre evolução da razão e fatores sociais, a teoria sociológica oferece um suporte indispensável à teoria pedagógica, permitindo também que se reformule o seu próprio modo de proceder. Assim conclui Piaget (1998, p. 140):

Foi precisamente este dado fundamental da sociologia do pensamento que os profissionais da pedagogia encontraram quando, depois de estabelecer que a criança não é passiva mas ativa e que a razão, longe de ser inata no individuo, elabora-se pouco a pouco, descobriram que a vida do grupo é o meio natural dessa atividade intelectual e a cooperação, o instrumento necessário para a formaçáo do pensamento racional [...]. 
Portanto, resumindo, o núcleo do terceiro argumento repousa na ideia de que o grupo é o "habitat natural" da formação do pensamento e a cooperação, o procedimento mais adequado para formá-lo. Isso me permite extrair a conclusão geral de que o trabalho cooperativo de grupo é fundamental para desenvolver na criança sua capacidade de julgamento. Assim arremata o genebrino seu argumento: "Pode-se, portanto, dizer, a nosso ver, que a cooperação é efetivamente criadora, ou, o que dá no mesmo, que ela [forma] a condição indispensável para a constituição plena da razão [...].” (PIAGET, 1998, p. 144) Com isso podemos ver o quanto esta posição de Piaget, que coloca o trabalho cooperativo de grupo na base de formação da racionalidade humana, está próxima da tese de Honneth sobre o papel normativo que a intersubjetividade de grupo desempenha na "boa" socialização humana.

\section{Considerações conclusivas}

Como forma de conclusão, eu gostaria de revelar agora os motivos de fundo que me levaram a empreender este percurso teórico iniciado com Honneth, passando por Winnicott e chegando até Piaget. Por um lado, vivemos num contexto social e pedagógico contemporâneo marcado por fortes tendências individualistas que, em nome do zelo excessivo por uma determinada forma de liberdade individual, tende a sufocar formas coletivas e solidárias de vida. Por outro, descortinam-se no horizonte do homem contemporâneo gigantescos problemas sociais e ambientais que obviamente não passam por soluções individuais, imediatistas e localizadas, mas exigem, sim, reflexão e saída coletiva.

Como contemporâneos, já tendo diante de nós experiências passadas, sabemos que a teoria não pode mais desempenhar a função salvífica a ela outrora atribuída. Mas, o fato de não ser mais tomada como a fonte exclusiva de redenção da humanidade, ela pode, sim, continuar servindo como luz que abre pequenas clareiras na imensa escuridão e mistério que domina as mais diferentes formas de vida do homem contemporâneo. É a convicção nesta pequena força da teoria que deve nos impulsionar a revisitar permanentemente os grandes autores e buscar em seus pensamentos clareiras que nos auxiliem a reanimar aquela fusão originária que está na base de nosso amadurecimento como seres humanos. Ora, como vimos, é tal fusão que nos permite seguir teimosamente na construção do humano que há entre nós, apesar da força embrutecedora crescente de nosso entorno.

Enfim, minha rápida revisitação a estes autores teve por finalidade convencer-me a mim mesmo e, na medida do possível, também aos leitores, sobre a força positiva que a intersubjetividade do grupo desempenha na construção de processos formativo-educacionais mais cooperativos e solidários. 
Formas de reconhecimento e força intersubjetiva de grupo

\section{Notas}

1. Para uma noção ampliada de mundo como horizonte ver Hans-Georg Gadamer (1999, p. 345).

2. Tomarei como referência específica o capítulo intitulado "O eu em nós: reconhecimento como força motriz de grupos" (Das Ich im Wir. Anerkennung als Triebkraft von Gruppen), p. 261-279. Como se trata de uma livre reconstrução, eu farei indicação da página somente quando se tratar da citação literal da passagem correspondente.

3. Vê-se neste ponto, nitidamente, a influência que a leitura habermasiana de Georg Herbert Mead exerce no pensamento de Honneth. O conceito de individuaçáo social formulado por Habermas (1997, p. 187-241) certamente é uma das fontes decisivas do modo refinado com o qual Honneth pensa a interação entre indivíduo e sociedade, buscando fugir de uma abordagem determinista.

4. Na parte final do ensaio em que estamos nos baseando, Honneth descreve duas formas de patologização do grupo (p. 277ss). A primeira dá origem a um tipo de personalidade que permanece no nível da idealização primitiva. Trata-se aí de um perfil psicológico que se apodera do outro, desconhecendo sua individualidade. Deste modo, ao experienciar a figura de um líder idealizado como onipotente, os membros deste grupo sentem-se eles próprios imaturos e incompetentes. A segunda forma de patologização do grupo resulta do predomínio de um tipo determinado de personalidade constituído pelas experiências sofridas de abuso ou abandono, possibilitando o desenvolvimento de um alto potencial de agressão incontrolada. Membros deste tipo de grupo tendem a projetar no mundo suas fantasias destrutivas, segundo as quais se veem constantemente ameaçados por inimigos externos.

5. Na referida obra Freud defende a tese de que ao fazer parte da massa (grupo) o indivíduo sofre uma transformação anímica que interfere no seu afeto e inibe sua capacidade de pensar. (FREUD, 1999, p. 95) Numa outra passagem, ele afirma que o principal fenômeno da psicologia das massas é a ausência de liberdade do individuo na massa (p. 104).

6. O interesse de Honneth pelo pensamento de Winnicott é antigo, remontando ainda ao seu trabalho pioneiro: Luta por reconhecimento (1992).

7. Contudo, uma leitura atenta de outros textos de Winnicott póe em questão esta interpretação de Honneth. Tal é o caso de Privaçâo e Delinquência (2002b, p. 215-226).

8. Do ponto de vista filosófico, ao fundamentar geneticamente sua teoria do conhecimento, Piaget é criticado por confundir problemas de validade com problemas de gênese, sendo acusado, por isso, de cometer a falácia genética. (KOHLER, 2008, p. 116)

\section{Referências}

FREUD, S. Massenpsyhologie und Ich-Analyse. Frankfurt am Main: Fischer Taschenbuch Verlag, 1999. [GW, Band XIII].

GADAMER, H. Die Vielfalt der Sprachen und das Verstehen der Welt. Tübingen: Mohr Siebeck, 1999. [GW, Werke 8].

HABERMAS, J. Nachmetaphysisches Denken. Philosophische Aufsätze. Frankfurt am Main: Suhrkamp, 1997. . Strukturwandel der Öffentlichkeit. Frankfurt am Main: Suhrkamp, 1990. 
HONNETH, A. Das Ich im Wir. Studien zur Anerkennungstheorie. Frankfurt am Main: Suhrkamp, 2010. kamp, 2005.

Verdinglichung. Eine anerkennungsthoretische Studie. Frankfurt am Main: SuhrKampf um Anerkennung. Zur moralischen Grammatik sozialer Konflikt. Frankfurt am Main: Suhrkamp, 1992.

KOHLER, R. Jean Piaget. Bern/Stuttgart/Wien: Haupt Verlag, 2008.

NUSSBAUM, M. El cultivo de la humanidad. Umn defensa clasica de la reforma en la educación liberal. Barcelona: Paidós, 2005.

PIAGET, J. Sobre a pedagogia. Textos inéditos. São Paulo: Caso do Psicólogo, 1998.

SCHARLAU, I. Jean Piaget zur Einführung. Hamburg: Junius Verlag, 1996.

SENNETT, R. O declinio do homem público. As tiranias da intimidade. São Paulo: Companhia das Letras, 1988.

WINNICOTT, D. Vom Spiel zur Kreativität. Stuttgart: Klett-Cotta, 2002a. . Privação e delinquência. São Paulo: Martins Fontes, 2002b.

YOUNISS, J. Soziale Konstruktion und psychische Entwicklung. Frankfurt am Main: Suhrkamp, 1994.

Recebido em 04 de julho de 2014.

Aprovado em 26 de junho de 2015.

DOI: http://dx.doi.org/10.1590/ES0101-73302015137308 